\title{
COOPERATION, COMPETITION, INDIVIDUALISM AND INTERPERSONALISM IN JAPANESE FIFTH AND EIGHTH GRADE BOYS *
}

\section{David SHWALB}

University of Michigan, Ann Arbor, USA

\section{Barbara SHWALB}

University of Utah, Salt Lake City, USA

\section{Koji MURATA}

Tokyo University, Japan

Revised version received August 1989

The study compared the expression of cooperation, competition, individualism and interpersonalism in Japanese youth. Forty-two Sth grade boys and 42 8th grade boys first completed two questionnaires about cooperation/competition and group/individualized activities. Their group structure was then coded (as working in trios, in duos, or separately) as trios of boys built houses with playing cards. The experimental design crossed instructions (1) to work individually or in a group and (2) compete or do one's own best. Subjects were questioned about their awareness of, liking for and preferences for the cooperative, individualistic, and group-centered aspects of the experimental tasks.

On orientation scales, 8 th graders chose equal numbers of individualistic and group-centered activities, while 5th graders chose more group activities. Both age groups strongly favored cooperative over competitive items. In group trials of the experiment, 8 th graders tended to work alone for greater proportions of time than did 5th graders. Questionnaire data indicated that (1) 8th graders reported greater enjoyment of the individualistic aspect of the task than did 5th graders, (2) both age groups evidenced a strong sense of interpersonalism, and (3) cooperation was rated more positively than competition at both ages. The study was discussed in relation to recent studies on Japanes school socialization and cooperation/competition.

* The extraordinary generosity of Tatsuo Yanagi made this study possible. The kindness of the pupils and staff of the Gakugei University-attached Takehaya Primary and Middle Schools, and the invaluable support of Hiroshi Azuma, Yoshimatsu Shibata, Masako Ishida, Kazuyoshi Furuhata, and Jun Nakazawa are also gratefully acknowledged. The first author was supported by a Fulbright Dissertation Grant, and the second author by a Japanese Monbusho fellowship at the time of this study.

Comments or requests for reprints should be sent to Dr. Barbara Shwalb, $115 \mathrm{MBH}$, Educational Studies, University of Utah, Salt Lake City, Utah 84112, USA. 
The Japanese 'educational miracle' (Lewis 1989b) has recently stimulated international research on academic achievement, while the study of Japanese social and personality development has become a secondary concern. The present study concerns the expression of cooperativeness, competitiveness, individualism and interpersonalism in the transition to Japanese adolescence. Fifth and 8th grade boys participated in an experiment working alone and as groups, in cooperative and competitive task settings. This developmental study contributes to the cross-cultural literature on cooperation and competition and to our understanding of Japanese social- and task-oriented behavior.

Cooperativeness is defined as behavior or attitudes favoring shared goals. Competitiveness is indicated by a desire to outdo others or gain recognition. Individualism is seen in tendencies to challenge personal standards or to work alone. The fourth term, 'interpersonalism', was coined in reference to the Japanese 'definition of self in terms of the relationships one has with others' (Befu 1986: 22), and is seen in the value placed upon group harmony and group activities.

\section{Cooperation, competition, individualism and interpersonalism}

A substantial body of Western and cross-cultural literature indicates that competitive game-playing behavior (e.g. Madsen and Lancy 1981) and competitive attitudes (Ahlgren and Johnson 1979) become stronger with age, particularly among males and in urban/Westernized populations (Mann 1979). In addition, pupils of all ages seem to respond more favorably to cooperative than to individualized learning activities (Graves and Graves 1984). Unfortunately, much of this literature is substantially flawed methodologically and conceptually. It is important to make a distinction between competition and individualism, because the two concepts have been confounded in many published studies. Knight and Kagan (1981) note that when children are not given the opportunity to behave individualistically (as in Madsen's studies) their competitive and cooperative tendencies are exaggerated. Many experiments give subjects just one choice, between cooperation and competition, although one's personality may actually combine cooperativeness, competitiveness, individualism and interpersonalism. The measures used in the present study allow the expression of all four tendencies. In addition, adolescents are conspicuously omitted from the experimental 
literature on cooperation and competition, and the present study addresses this gap as well.

Japanese orientations toward self, others, and tasks

\section{Japanese children}

Most relevant to our concern with cooperation, etc., are several recent psychological studies on Japanese social- and task-related behavior. These have focused entirely on preschoolers and primary school children. It is clear from such studies that Japanese families and schools foster task involvement, i.e. concentration on one's work and perseverance towards long-term goals (Holloway 1988; Nicholls 1983). Conversely, they discourage ego-involvement, a preoccupation with one's self and abilities. This is important for our discussion because task involvement has been related more to cooperative than competitive reward structures. Cooperation is thought to focus children's thinking on effort and improvement, while competition leads one to center on ability and comparisons with peers (Nicholls 1983). Indeed, data from numerous societies indicate that pupils work harder and perform better in cooperative groups than as competitors (Graves and Graves 1988). Research is beginning to indicate that Japanese schools foster task involvement by stressing groups.

While cooperativeness, competitiveness, interpersonalism and individualism are all goals of Japanese socialization, Hamilton et al. (in press) have shown objectively that primary schools give precedence to cooperation and interpersonalism over individualism and competition. In Japan, packaged Western methods (e.g. 'Jigsaw', 'TGT', etc.) of cooperative learning are seldom used (Sugie 1988), but the group is emphasized implicitly in basic classroom dynamics. The importance of the groups was observed among 5th graders (Hamilton et al.). Compared with American teachers, Japanese teachers more often (1) addressed groups rather than individuals, and (2) checked pupils' work in a group rather than an individual format. In addition, they observed that teachers of Japanese 5th graders emphasized persistence (i.e. task involvement) and downplayed individual evaluation (ego involvement). Finally, the teachers they observed minimized individual differences in 
achievement by organizing mixed-ability work groups, which also encourages task involvement more than social comparisons.

This is not to say that competition and individualism are absent from school experiences. All Japanese pupils receive individual evaluation in the form of report cards (Leestma et al. 1987), so that individual achievement is formally (though privately) recognized. Individual and competitive achievement are also publicly displayed in nonacademic settings such as athletic meets (Cummings 1980). But as Lewis (1989a) has documented, in preschool and from early elementary school the focus is on working well in groups rather than on academic competition. Based on such research, the 5 th graders sampled here could be expected to express cooperativeness and interpersonalism and a strong task involvement rather than competitiveness or individualism.

\section{Japanese adolescents}

While the literature on adolescence is seldom empirical or psychological, it suggests the emergence of individualism and competition, as 'the structure of schooling changes radically during middle school' (Holloway 1988: 328). Egalitarianism and interpersonalism are basic to the philosophy of elementary school in Japan (Cummings 1980), but in secondary school pupils are sorted into ability tracks which heavily influence their future lives (Rohlen 1983). The pupil who fails to pass a high school entrance exam will be forced to attend a technical high school and be ineligible for college and or high social/occupational status. The period of maximum pressure for high school entrance examination preparation begins in the eight grade (Singleton 1982). Pupils are required to study long hours every night in isolation, striving intensely for academic excellence (Kubo 1981). Two recent surveys of Japanese primary/secondary school pupils indicate that (1) beginning in early adolescence competition is conceptualized in two forms - between-group and individualized competition (B. Shwalb and D. Shwalb 1985), and (2) that between-group group competition is particularly valued by 7 th through 9 th grade pupils (Shwalb et al. 1987). Based on the above information, we predicted that 8 th graders would display more competitive and individualistic behavior and orientations than would 5 th graders, under controlled experimental conditions. 


\section{Methods}

\section{Subjects}

Participants were 84 boys from a school complex affiliated with a national (public) university, in central Tokyo. ${ }^{1}$ All 5 th grade boys $(n=42)$ and all boys from two (of four) 8 th grade classrooms $(n=42)$ participated. Mean ages of the two groups were 11 years 5 months and 14 years 6 months, respectively. Only males were sampled because of severe time restrictions and the unavailability of several female pupils from these classes. $^{2}$

\section{Procedures}

To minimize social demands in the experimental setting, and on all self-report measures, subjects were told that nobody at school would see any of their behavior, and pupils' names were not requested at any point.

\section{Experimental tasks}

Boys were randomly assigned to same-grade, same-homeroom triads, and were videotaped constructing card houses with playing cards during two experimental sessions. Each boy was given a deck of 52 standard-size cards and told to build houses with them, a task with which none of the 84 subjects reported any prior experience. The experimenter demonstrated how five cards could be combined lining them up perpendicularly to one another, and instructed subjects that they should line up or stack as many cards as possible, in any configuration.

The experimental design crossed group and individualized instructions with instructions to 'pile up the most cards' (i.e., outdo others) or 'do your own best' (i.e., work without regard to others' performance). Specifically, boys performed under the following four 8-minute conditions, randomized for order within and between sessions:

\section{Trial 1}

Individual Non-competitive ('Work separately to do the best you can'.)

\section{Trial 2}

Individual Competitive ('Work separately to see who is the best in your group'.)

1 Elevation to high school from the middle school at this complex involves the same entrance exam system that marks education in most urban public schools. For both public and university. attached schools the Japanese Education Ministry strictly regulates the curriculum, which is geared towards this selection process. The senior author informally observed and conversed with pupils and teachers at public schools and the complex at which the experiment was conducted, and found over the course of one year of weekly observations that social and academic experiences in the two types of schools are quite similar.

2 Access to subjects was restricted to after-school hours, and to the number of subjects whose data is reported. In addition, no female data was collected because research on group dynamics indicates major sex differences in cooperation/competition (Weisfeld 1986), such that our male and female data would not be collapsable. 
Trial 3

Group Non-competitive ('Work together as a group to do the best you can'.)

\section{Trial 4}

Group Competitive ("Work together as a group to outperform other groups'.)

At each of the two sessions boys were assigned to one group trial and one individualized trial.

The boy who stacked the most cards under the Individual Competitive trial was praised for his accomplishment, and groups that stacked all their cards (at least once) under the Group Competitive trial were also praised, to remind subjects of the competitive nature of these two trials. At the end of each individual trial, each boy was asked how many cards he stacked in his best product, and groups were asked for similar information after group trials, as a further reminder of the evaluative aspect of the trials.

\section{Post-experimental questionnaires}

After each of the four trials, participants were given the same post-treatment questionnaire. This asked pupils for their perceptions of the triad's structure ("Which of these best describes how the three of you worked: individually/a pair vs. a singleton/a united group?'). Finally, boys rated their feelings of cooperation, competition, and individuation during the trial ('How much did you feel like you were joining forces/ outdoing your partners/working alone?').

At the conclusion of the two trials at each session, a post-session questionnaire was administered. Boys indicated preferences for the group or individualized trial that day ('Which of the two tasks did you prefer today?' and 'If you could try it again, which task would you repeat?'). They then ranked from 1 to 3 their overall enjoyment for the individualistic, cooperative, and competitive aspects of the session ("Which of the three was most/second most enjoyable for you today: Doing your own best/joining forces with others/competing with friends?').

\section{Orientation scales}

During an extended homeroom period, all pupils in the two 5th grade and two 8th grade classrooms completed two questionnaires. The first form, the cooperation/ competition questionnaire, consisted of 24 items describing cooperative or competitive school behaviors (e.g., 'helps the teacher with his/her work'; 'gets better grades than friends on tests'). These items had been generated by a national sample of Japanese public school teachers (D. Shwalb and B. Shwalb 1985). Participants rated each activity on a 5-point scale in terms of personal importance, and then selected and ranked the ten most important of these same 24 items.

On the second form, adapted from Zander (1971), participants indicated preferences for either a group activity or a related individual activity from each of ten item pairs. An example is "If I were running, I would rather be in (a) an individual race; (b) a relay race'. Of these choices, group activities are more indicative of interpersonalism. 


\section{Results}

\section{Group structure}

Coders calculated the durations and frequencies of three categories of group structure during the two group trials; and inter-rater reliability for all the videotaped data on half the groups averaged 0.94 for the onset of the three categories. Two-way repeated measures analyses of variance, for the effects of age level and competitive/ non-competitive trials, were conducted on the proportions of time during which cards were being stacked in each of three structures:

(1) 'Triad': The card products of all three boys were linked together into one product.

(2) 'Dyad': The products of two boys were linked together, and

(3) 'Isolate': Three distinct card houses were visible, with each boy working on his own product.

These categories are similar to those used in previous studies of peer play. Due to the small sample size and unlikelihood of multivariate normality (Harris 1985), univariate analyses were most appropriate.

The most common group structure at both ages was 'triad', but 8th graders spent a significantly higher proportion of time than 5th graders 'isolate' or in 'dyads'. Fifth graders worked as triads for a significantly larger proportion of the time, possibly reflecting more interpersonalistic orientation. Subjects' self-reported perceptions of group structure corroborated these age effects. The proportions, standard deviations, and analysis of variance for age effects in observed group structure are presented in table 1. There was no effect on group structure for competitive versus non-competitive task instructions.

\section{Post-treatment questionnaires}

For post-treatment and post-session self-reports, responses were averaged for each group. A series of $t$-tests indicated that while fifth graders felt about the same degree of cooperation, competition and individuation during the tasks, eighth graders felt most strongly that they had 'worked alone'. For fifth graders, mean ratings of all three aspects of the trials were equal (all $t s<1$ ). Eighth graders rated the competitive and cooperative aspects of the trial equally, $t(42)=-0.03, p=0.97$. They also reported

Table 1

Percentages of task time by group structure and age level.

\begin{tabular}{llrllll}
\hline & Fifth grade & & \multicolumn{2}{c}{ Eighth grade } & Age effect \\
\cline { 2 - 3 } & Mean & $S D$ & & Mean & $S D$ & \\
\hline Triad & 74.0 & 23.0 & 51.6 & 31.6 & $F=7.27$ \\
Dyad & 3.3 & 4.2 & 8.9 & 12.0 & $F=6.64$ \\
Isolate & 9.2 & 14.3 & 22.6 & 19.6 & $F=6.60$ \\
\hline
\end{tabular}

Note: For all age effects $d f s=1,26, p s<0.05$. 
Table 2

Perceptions of the competitive, cooperative and individualistic aspects of the experimental task.

\begin{tabular}{lllcc}
\hline Aspect & Fifth grade & Eighth grade & $F$ & $p$ \\
\hline Competitive & $3.65(1.26)$ & $2.87(0.73)$ & 13.47 & $<0.001$ \\
Cooperative & $3.71(1.21)$ & $2.77(0.79)$ & 7.24 & $<0.01$ \\
Individualistic & $3.77(1.11)$ & $3.50(0.75)$ & ns & - \\
\hline
\end{tabular}

Note: $d f s=1,26$. Five-point scale for perception: 5 - felt strongly; 1 - didn't feel much. Standard deviations are given in parentheses.

stronger individualistic feelings than cooperative feelings, $t(42)=4.01, p<0.001$, or competitive feelings, $t(42)=4.24, p<0.001$. This is congruent with the above findings of more individualistic behavior among older boys. The means, standard deviations, and significance tests for age effects, for the post-treatment questionnaire responses, are given in table 2.

\section{Post-session questionnaires}

The mean rankings and standard deviations of preferences for group versus individual trials, and enjoyment of the competitive, cooperative and individualistic aspects of the trials are given for each grade level in table 3.

\section{Preferences for working alone versus in a group}

$T$-tests were conducted on the null hypothesis that mean preferences equalled 1.5 (which would indicate equal liking for group and individual trials). Fifth graders preferred working as a group (i.e. interpersonalism) over working alone, $t(14)=2.27$, $p<0.05$, while 8 th graders enjoyed group and individual trials equally, $t(14)=0.76$, $p=0.46$.

Table 3

Preferences for group versus individual treatments, and rankings of the cooperative, competitive and individualistic aspects of trials.

\begin{tabular}{lll}
\hline Response & Fifth grade & Eighth grade \\
\hline Indiv./group trial preference & $1.66(0.07)$ & $1.56(0.10)$ \\
Individualistic aspect & $2.23(0.30)$ & $1.80(0.42)$ \\
Competitive aspect & $2.29(0.35)$ & $2.35(0.49)$ \\
Cooperative aspect & $1.64(0.56)$ & $1.87(0.53)$ \\
\hline
\end{tabular}

Note: Preferences: 1 - individual trials; 2 - group trials. Rankings of treatment aspects: 1 - most enjoyed; 2 = second most enjoyed; 3 - least enjoyed. SDs given in parentheses. 
Enjoyment of cooperation, competition, and individuation

Paired $t$-tests at each grade level indicated that fifth graders enjoyed the cooperative aspect of sessions significantly more than either the competitive aspect, $t(14)=-3.06$, $p<0.01$, or the individualistic aspect, $t(14)=2.79, p<0.05$, and that they enjoyed the competitive and individualistic aspects equally, $t(14)=0.44, p=0.67$. Eighth graders enjoyed the individualistic aspect equally well as the cooperative aspect, $t(14)=-0.32$, $p=0.75$, and more than the competitive aspect, $t(14)=-2.70, p<0.05$.

These findings indicate that (1) in 5 th grade group experiences and cooperation are enjoyed most, and (2) in 8th grade group and individual tasks are equally enjoyable while both individualistic and cooperative activities are enjoyed more than competitive activities. Examination of the means also shows that both age groups ranked competition as the least enjoyable aspect of the sessions.

\section{Orientation scales}

\section{The cooperation / competition questionnaire}

Previous studies (D. Shwalb and B. Shwalb 1985; Zander 1971) established the reliability and validity of the two orientation scales. Factor analyses on the cooperation/competition form indicated high loadings for nine items each, on cooperative and competitive factors. Two indices counted the numbers of cooperative and competitive items, respectively, ranked among the ten most important. Analyses of variance on the two indices formed from the cooperation/competition questionnaire, reported in table 4, showed no major differences between the orientations of 5 th and 8 th graders $(F \mathrm{~s}<1)$. The data indicate that cooperative activities are more positively valued at both age levels than are competitive activities. Chi-square analyses on each of the 24 items revealed age differences for only three items: "participating in homeroom activities', $\left.\chi^{2}(1, N=84)\right)=8.77, p<0.001$; 'preparing for entrance examinations', $\chi^{2}$ $(1, N=84))=19.01, p<0.001$; and 'helping a peer weaker in sports', $\chi^{2}(1, N=84)$ ) $=19.01, p<0.001$. Eighth graders more often ranked 'homeroom activities' and 'entrance examinations' in the top ten for importance, while 5th graders more often than 8 th graders ranked 'helping a peer' as important.

\section{Table 4}

Analyses of variance for grade level effects on orientation questionnaire indices.

\begin{tabular}{llrccc}
\hline Scale & $\begin{array}{l}\text { Source of } \\
\text { variance }\end{array}$ & $d f$ & MS & $F$ & $p$ \\
\hline Cooperative & Grade & 1 & 5.76 & 1.65 & 0.21 \\
Top ten & Error & 82 & 3.68 & - & - \\
Competitive & Grade & 1 & 0.05 & 0.01 & 0.94 \\
$\begin{array}{l}\text { Top ten } \\
\text { Individualistic }\end{array}$ & Error & 82 & 7.17 & - & - \\
choice & Grade & 1 & 53.44 & 13.78 & $<0.001$ \\
\hline
\end{tabular}




\section{The group/individual questionnaire}

On an analysis of variance for the number of individualistic items chosen (out of ten), also reported in table 4, eighth graders selected significantly more individualistic activities than did 5 th graders, $F(1,82)=13.78, p<0.001$ (means: 5 th grade $=2.83$ items, 8 th grade $=4.43$ items; $S D$ s: 5 th grade $=2.06$, 8 th grade $=1.88$ ). The null hypothesis, that subjects would choose equal numbers of individualistic and groupcentered items, cannot be rejected for 8 th graders, $t(42)=1.04, p=0.30$; they manifest no clear preference for either style. But 5 th graders chose group-centered items significantly more than individualistic items, $t(42)=4.33, p<0.001$.

\section{Discussion}

\section{Emergence of individualism}

On every measure, 8 th graders were more individualistic than were 5 th graders. This was seen as the structure of their groups, their consciousness of working alone, their preference for and enjoyment of individualized trials, and in responses on a general attitudinal scale. Individualism ('jikoshugi') is a newly-invented word in the Japanese language (Hamaguchi 1977), and it is not encouraged among preadolescents at home or school. But it begins to take hold as an alternative value orientation in early Japanese adolescence (Cummings 1980), as our data illustrate.

As time invested in study and homework increase substantially in adolescence, Japanese pupils spend more time in isolation, forfeiting time they had allotted to family, friends or school clubs (Kubo 1981). The behavior and orientations reported here may result from the fact that 8 th graders are rewarded for following family/peer norms to work hard alone.

\section{Interpersonalistic individualism}

Emotional ties formed in childhood at Japanese schools often last a lifetime. School clubs, team activities and extensive classroom committee work provide both 5 th and 8 th graders with opportunities for solidarity (Singleton 1982; Cummings 1980). So the individualism that emerges in early adolescence is strongly tinged by interpersonalism which remains a psychological characteristic of the Japanese throughout the lifespan (Befu 1986). 
Fifth-grade boys selected more group than individualized activities on the attitudinal questionnaire, and preferred group over individualized tasks on the post-session questionnaire. However, it was not the case that 5 th graders had no sense of individual self, or that 8 th graders were entirely individualistic. Eighth graders' individualistic and groupcentered preferences were approximately equal, suggesting that by early adolescence the two orientations coexist with equal importance.

\section{Cooperativeness, competitiveness and individualism}

Data on Western boys tend to show a trend towards increasing competitiveness in adolescence (Graves and Graves 1984), but this was not the case in the present study for two reasons. First, on self-report measures and in most Western game-playing tasks thought to tap competitive motivation, behavior which maximizes the individual's rewards (individualistic acts) are defined as competitive. But seeking a reward higher than one's partner in a game may have nothing to do with beating a rival, and more to do with individual excellence. So age trends described elsewhere as toward competitiveness may actually reflect a trend toward individualism. A second explanation concerns cultural values. The value placed in Japanese schools on cooperativeness is so strong that it is unaffected by competitive counter-pressure (Kataoka 1979). Because of early incorporation of social norms and their consistent reinforcement over the years, cooperative and competitive orientations may be fixed prior to 5 th grade. Children may wish to behave more competitively with age, but even Japanese preschoolers have learned that cooperativeness is a more desirable trait than competitiveness (Lewis 1989b).

\section{Implications}

The following trends were notable comparing male Japanese 5 th and 8th graders: (1) individualistic orientations and behavior were more notable in older boys; (2) group-centered orientations and behavior gave some ground to individualism, but were still an integral aspect of behavior in young adolescents; (3) competitiveness was treated differently from individualistic striving and was evaluated negatively at both ages; and (4) cooperation was highly evident and valued at both ages. 
These results may reflect the influences of classroom experiences on orientations toward the self, peers, and tasks. The extensive observations of Hamilton et al. (in press) and Lewis (1989b), and the theorizing of Holloway (1988) and Nicholls (1983) led us to expect that 5th graders would be strongly group-oriented and task-oriented, but not self-oriented (ego-involved). This was indeed borne out by the data. Many younger boys reported an awareness of belonging to a trio even when they worked individually and subjects were coded as 'on-task' more than $95 \%$ of the time, under every condition. Recent research on younger children has not been paralleled by observational studies in secondary schools, although Sakamoto (1985) has described secondary school pupils' study behavior as 'passive and individualized'. The literature on Japanese adolescence, which is largely descriptive and anecdotal, suggests that individualism and competitiveness would be strongly expressed among the 8 th graders. Clearly the 8 th graders were more individualistic than the 5 th graders, but their individuality was not entirely at the expense of cooperativeness or interpersonalism. Meanwhile, competitiveness was seldom expressed by boys of either age. Since cooperation may be overwhelmingly socially desirable compared to competition, new and unobtrusive measures are needed to tap Japanese intergroup and individual competitiveness in adolescents.

This study demonstrated that Japanese children and adolescents differ in the relative value they place on cooperation, individualism and interpersonalism. Therefore adolescents must be the focus of future research on Japanese social and personality development. In addition, the way in which cooperative, competition, individualism and interpersonalism come to coexist in the adult personality may vary between cultures, and the study of cultural and developmental antecedents of such coexistence should become a fruitful arena for cross-cultural research.

\section{References}

Ahlgren, A. and D. Johnson, 1979. Sex differences and competitive attitudes from the 2 nd through the 12th grades. Developmental Psychology 15, 45-49.

Befu, $H ., 1986$. 'The social and cultural background of child development in Japan and the United States'. In: H. Stevenson, H. Azuma and K. Hakuta (eds.), Child development and education in Japan. New York: W.H. Freeman. 
Cummings, W.K., 1980. Education and equality in Japan. Princeton, NJ: Princeton University Press.

Graves, N.R, and T.D. Graves, 1984. Preferences for cooperative, competitive and individualistic learning situations. Newsletter of the International Association for the Study of Cooperation in Education 5(3/4), 19-20.

Graves, N.R, and T.D. Graves, 1988. Cooperative learning around the world. Newsletter of the International Association for the Study of Cooperation in Education 9(1), 4-8.

Hamaguchi, S., 1977. Nihon-rashisa no sai-hakken [What is Japanese? A rediscovery]. Tokyo: Nihon Keizai Shimbunsha.

Hamilion, V.L., P.C. Blumenfeld, H. Akoh and K. Miura, in press. Group and gender in Japanese and American elementary classrooms. Journal of Cross-Cultural Psychology.

Harris, R.J., 1985. A primer of multivariate statistics. New York: Academic Press.

Holloway, S.D., 1988. Concepts of ability and effort in Japan and the United States. Review of Educational Research 58(3), 327-345.

Hsu, F.L., 1983. Rugged individualism reconsidered. Knoxville: University of Tennessee Press.

Kataoka, N., 1979. Kyoso to kyodo [Competition and cooperation]. Tokyo: Reimei Shobo.

Knight, G.P. and S. Kagan, 1981. Behavioral and sociometric methods of identifying cooperators, competitors, and individualists: Support for the validity of the social orientation construct. Developmental Psychology 17, 430-433.

Kubo, Z., 1981. Kyosoteki jinzai senbatsu shita no kyoiku kohai ni doh tachimukauka [How shall we face the educational breakdown caused by the competitive human selection system?]. Kyoiku 402, 33-49.

Leestma, R, R.L. August, B. George and L. Peak, 1987. Japanese education today. Washington, DC: US Government Printing Office.

Lewis, C.C., 1989a. Review of T. Horio, Educational thought and ideology in modern Japan, and R. Lynn, Educational achievement in Japan. Monumenta Nipponica 44(1), 124-128.

Lewis, C.C., 1989b. From indulgence to internalization: Social control in the early school years. Journal of Japanese Studies 15(1), 139-157.

Madsen, M. and D.F. Lancy, 1981. Cooperative and competitive behavior: Experiments related to ethnic identify and urbanization in Papua, New Guinea. Journal of Cross-Cultural Psychology $12,389-408$.

Mann, L., 1979. 'Cross-cultural studies of small groups'. In: H. Triandis and R. Brislin (eds.), Handbook of cross-cultural psychology (Volume 5): Social psychology. Boston, MA: Allyn and Bacon.

Nicholls, J.G., 1983. 'Concepts of ability and achievement motivation: A theory and its implications for education'. In: S.G. Paris, G.M. Olson and H.W. Stevenson (eds.), Learning and motivation in the classroom. Hillsdale, NJ: Erlbaum.

Rohlen, T.P., 1983. Japanese high schools. Berkeley, CA: University of California Press.

Sakamoto, T., 1985. Characteristics of Study skills in Japanese pupils. Evaluation in Education 9(3), 243-251.

Shwalb, B.J. and D.W. Shwalb, 1985. The development of cooperation and competition in Japanese schools: Two national surveys. Evaluation in Education 9(3), 285-299.

Shwalb, D.W. and B.J. Shwalb, 1985. Japanese cooperative and competitive attitudes. Age and gender effects. International Journal of Behavioral Development 8, 313-328.

Shwalb, D.W., B.J. Shwalb and J. Nakazawa, 1987. Cooperative and competitive orientations of Japanese 7th-12th graders: A three-year survey. Paper presented at the meeting of the International Society for the Study of Behavioral Development, Tokyo, Japan.

Singleton, J., 1982. Nichu: A Japanese school. New York: Holt, Rinehart and Winston.

Sugie, S., 1988. Cooperative learning in Japan. Chukyo University Bulletin of the Faculty of Liberal Arts 29(2), 121-154. 
Weisfeld, C.C., 1986. Female behavior in mixed-sex competition: A review of the literature. Developmental Review 6, 278-299.

Zander, A., 1971. Motives and goals in groups. New York: Academic Press.

Cette étude a comparé l'expression de coopération, de compétition, d'individualisme et d'interpersonalisme, entre des Japonais pré-adolescents et des adolescents. Quarante-deux garçons d'environ 11 ans et quarante-deux garçons d'environ 14 ans ont d'abord rempli deux questionnaires concernant des activités de coopération/compétition et de groupe/individuelles. Leur conduite a été alors codifiée (travaillant soit en triade, en dyade ou individuellement) comme des trios de garçons construisant des maisons avec des jeux de cartes. Le schème experimental a fait interagir des instructions pour travailler seul ou en groupe et le fait d'entrer en compétition ou de faire de son mieux. Enfin, les sujets on été interrogés sur leur connaissance de et leur préférence quant aux aspects coopératif, compétitif, et individualiste, ainsi que les aspects centrés sur le groupe des tâches expérimentales.

Sur des échelles d'orientation, les garçons de 14 ans ont choisi un nombre égal d'activités individualistes et d'activités de groupe, tandis que ceux de onze ans ont choisi les activités de groupe. Les deux groupes d'âge ont clairement favorisé la coopération plutốt que la compétition.

Dans les essais en groupe, les garçons de 14 ans avaient tendance à travailler seuls ou dans des coalitions à deux contre un pendant plus longtemps que ceux de 11 ans. Les résultats des questionnaires ont indiqué que (1) les plus agés ont rapporté avoir plus de plaisir à travailler seuls que les plus jeunes, (2) le travail en groupe était préféré, même chez les plus âgés, (3) la compétition était perçue d'une façon négative par les deux groupes, (4) la coopération était évaluée positivement par les deux groupes. Les résultats sont discutés en rapport avec les études japonaises récentes sur la socialisation scolaire et avec les d́tudes interculturelles occidentales sur la coopération et la compétition. 